UCRL-21132

P.O. 1184903

$$
\begin{aligned}
& \text { Doroged } \\
& \text { JUL } 101989
\end{aligned}
$$

\title{
Modeling of Subsurface Geology in Medicine Lake, California
}

\author{
J. A. Rial \\ N. Saltzman \\ Dept. of Geology \\ University of North Carolina \\ Chapel Hill, NC
}

July 26, 1988

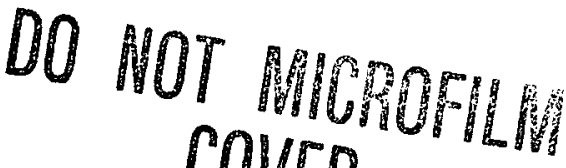 COVER}

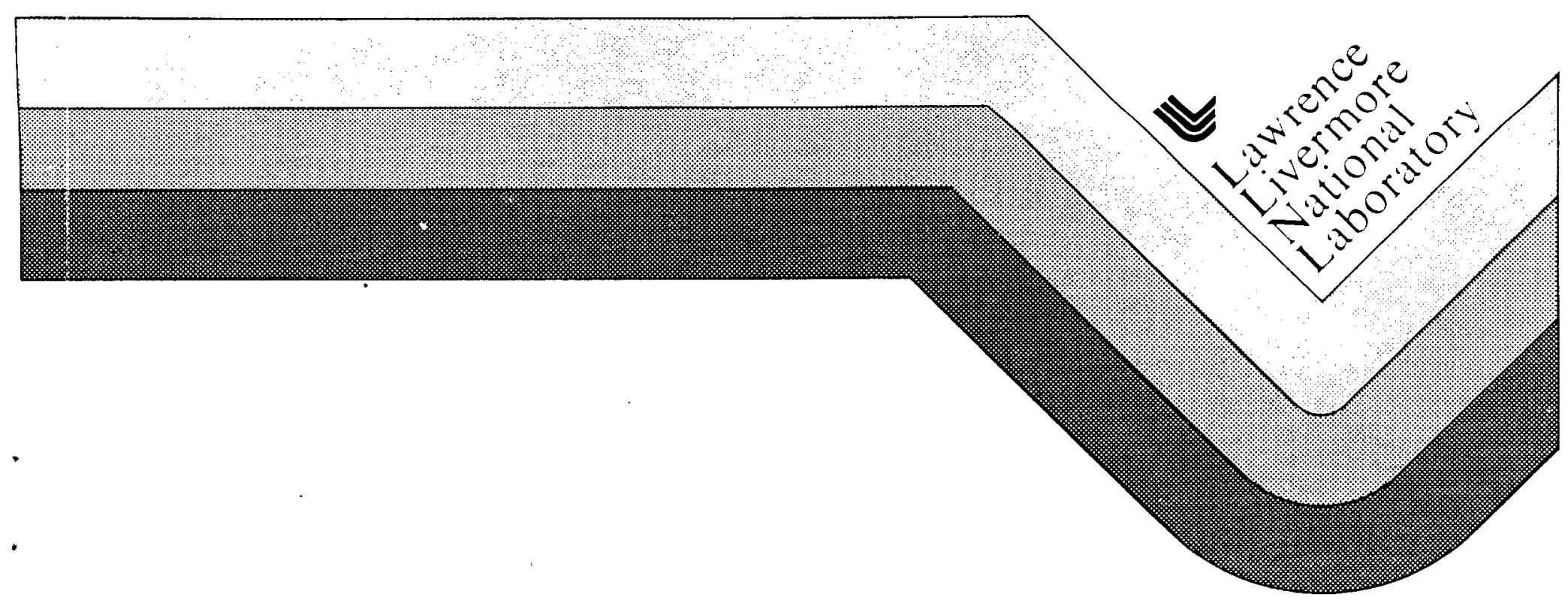


DISCLAIMER

Work performed under the auspices of the U.S. Department of Energy by Lawrence Livermore National Laboratory under contract number W-7405-ENG-48.

This document was prepared as an account of work sponsored by an agency of the United States Government. Veither the United States Government nor the University of California nor any of their employees, makes any warranty, express or implied, or assumes any legal liability or responsibility for the accuracy. completeness, or usefulness of any information, apparatus, product, or process disclosed, or represents that its use would not infringe privately owned rights. Reference herein to any specific commercial products, process, or service by trade name, trademark, manufacturer, or otherwise. does not necessarily constitute or imply its endorsement. recommendation. or favoring by the United States Government or the University of California. The views and opinions of authors expressed herein do not necessarily state or reflect those of the United States Government or the Lniversity of California, and shall not be used for advertising or product endorsement purposes. 


\section{DISCLAIMER}

This report was prepared as an account of work sponsored by an agency of the United States Government. Neither the United States Government nor any agency Thereof, nor any of their employees, makes any warranty, express or implied, or assumes any legal liability or responsibility for the accuracy, completeness, or usefulness of any information, apparatus, product, or process disclosed, or represents that its use would not infringe privately owned rights. Reference herein to any specific commercial product, process, or service by trade name, trademark, manufacturer, or otherwise does not necessarily constitute or imply its endorsement, recommendation, or favoring by the United States Government or any agency thereof. The views and opinions of authors expressed herein do not necessarily state or reflect those of the United States Government or any agency thereof. 
Modeling of Subsurface Geology in Medicine Lake, California

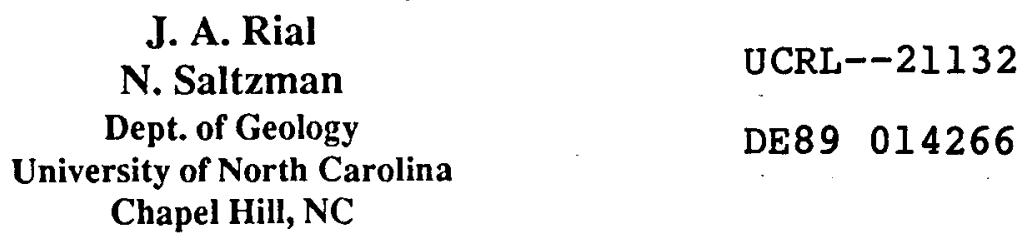

\section{Introduction}

In this document we present the results of our analysis of data from 16 three-component seismometers and 8 dynamite explosions around the Medicine Lake volcano's Glass Mountain in northern California. The Medicine Lake volcano is located just northeast of the southeastward-trending Cascade Range of shield and small composite volcanoes (Fig. 1). It is a Mio-pliocene shield volcano, which has been active in the last two million years with eruptions of rhyolitic, andesitic, and basal-tic lava. Glass Mountain, where the receivers for this experiment were located, is a large andesitic flow. Gravity and refraction data [Zucca et al., 1986] suggest that beneath the Medicine Lake volcano there is a highvelocity shallow pluton, probably composed of basaltic and rhyolitic sills and dykes. The refraction data also suggest a fault beneath the volcano.

\section{Data Analysis}

Sixteen receivers and 8 shot points comprise the original data set. The receivers were located within a circle with a radius of about $5 \mathrm{~km}$. The shots were located around the receivers at a distance of approximately $50 \mathrm{~km}$. Only 7 receivers and 4 shot points were useful for this study. Most of the rest were either dead recordings or extremely noisy.

The spectra of all the data were examined. Two predominant features were found, a notch in the spectra at around $6 \mathrm{~Hz}$ and a tailing off of intensity between 10 and $15 \mathrm{~Hz}$.
Some typical spectra are shown in Fig. 2.

Since different frequencies are affected by different sacle subsurface structures, the frequency ranges $2-6 \mathrm{~Hz}$ and $6-15 \mathrm{~Hz}$ were separately bandpass filtered using two-pass, four-pole Butterworth filters with corners at 2 and $6 \mathrm{~Hz}$ and at 6 and $15 \mathrm{~Hz}$. From what is known of the local velocity structure [Zucca et al., 1986], the frequency range $6-15 \mathrm{~Hz}$ corresponds to wavelengths of about $1 \mathrm{~km}$ or less. Since this is slightly less than the average distance between receivers, $1.74 \mathrm{~km}$, it is expected to be a good frequency range for illuminating the structure beneath the receivers.

The polarization of the first $\mathrm{P}$-wave motion and the first few $\mathrm{P}$-wave cycles of each record were analyzed. Determination of the first $\mathrm{P}$-wave polarization direction was made by a combination of visual and computer analysis. The visual determination was made from plots of the particle motion in the three perpendicular planes: horizontal, east-vertical, and north-vertical. From these, the threedimensional particle motion can be visualized. Figure 3 shows some typical plots. The computer analysis of the data consisted of determining the time, direction, and magnitude of the particle's largest displacements from rest. The directions and times of the first $\mathrm{P}$ wave motions obtained were compared to those obtained from visual examination. The results were usually very similar and records with discreprancies that could not be resolved were not included in the final maps. Results of this analysis are shown in Figs. 4 and 5. The arrows are projections of the first $\mathrm{P}$-wave motion directions on the horizontal plane. The magnitudes in the horizontal plane are normal- 


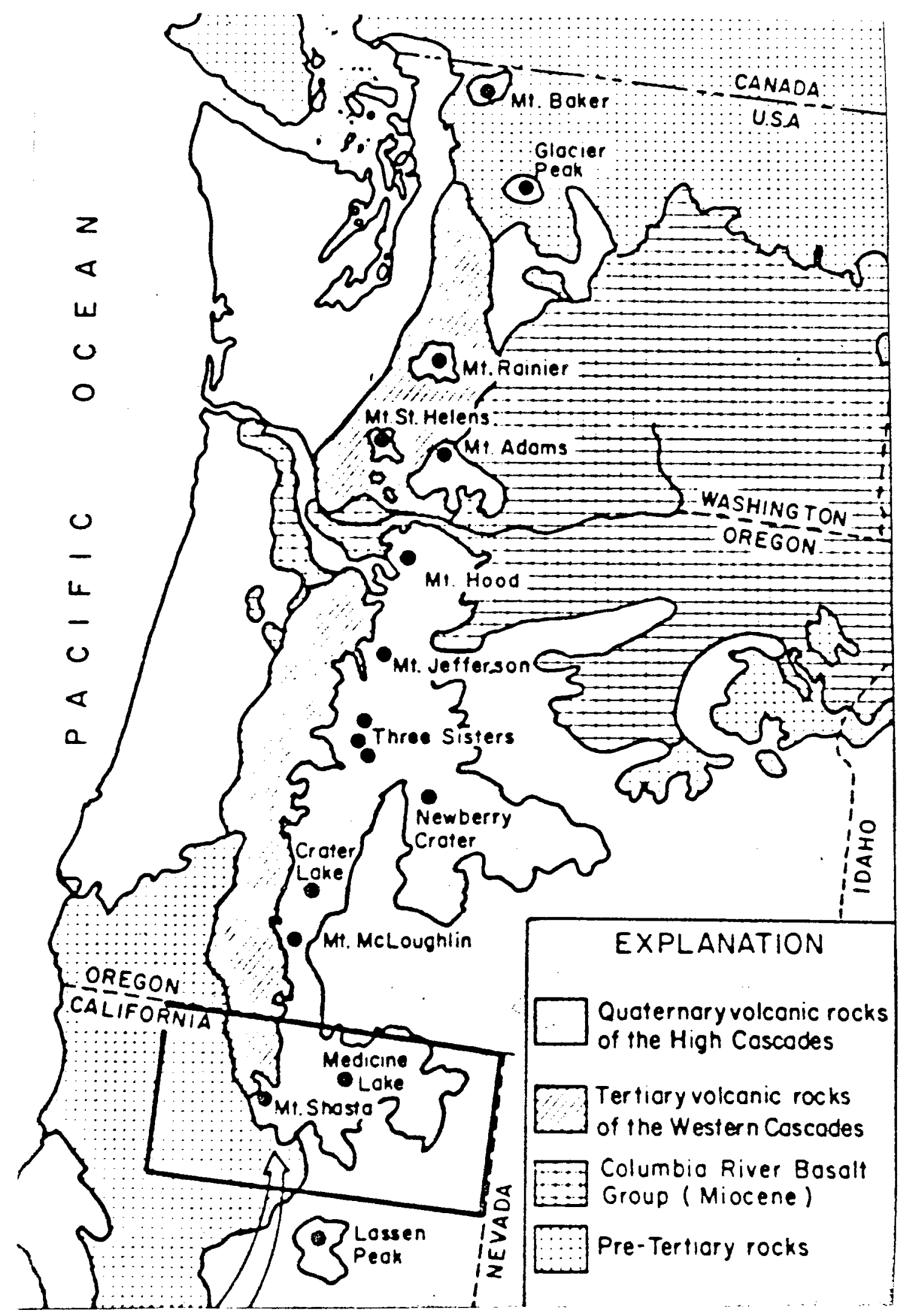

Figure 1. Location of the Medicine Lake volcano in northern California. 

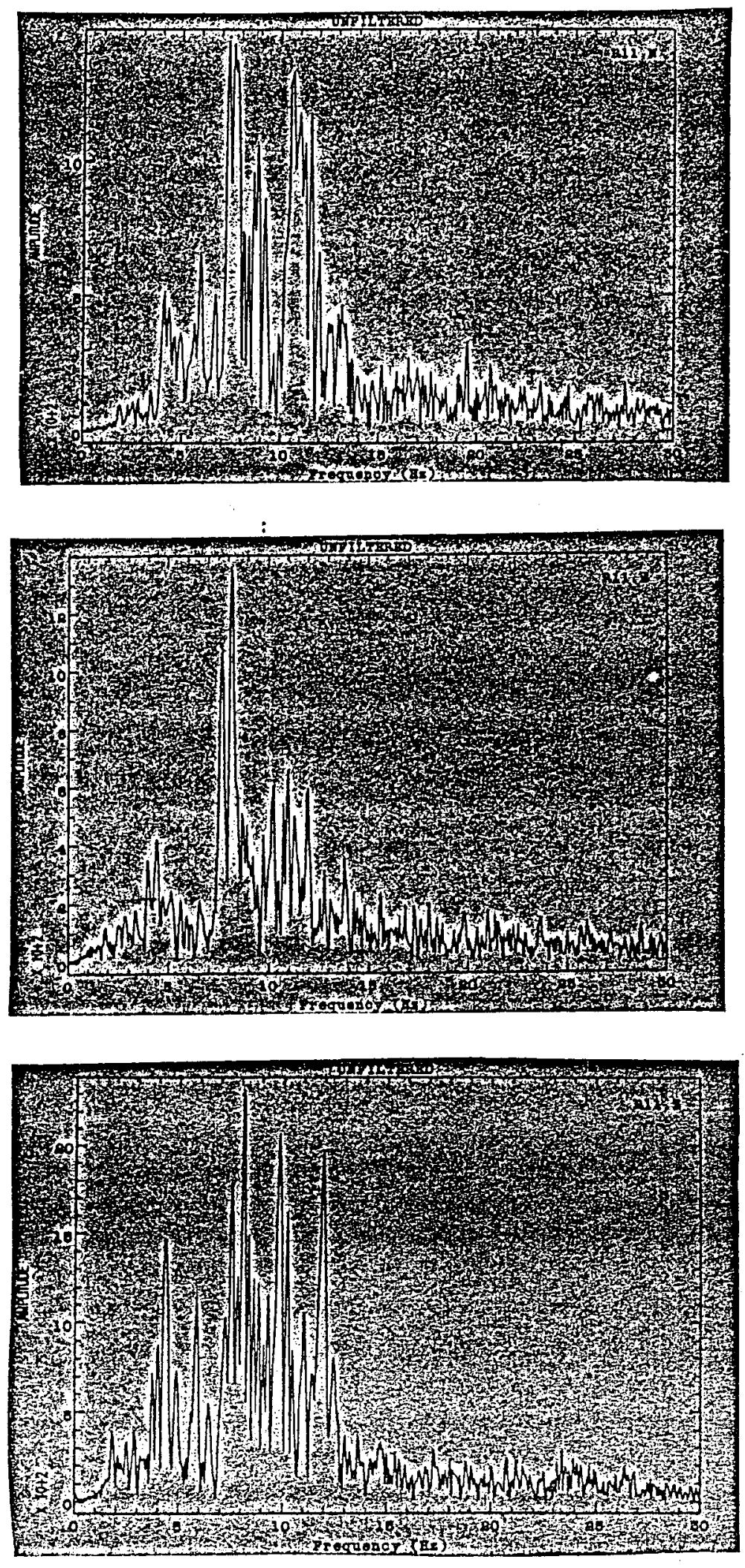

Figure 2. Typical frequency spectra. This is station 11 , shot 2 , vertical, north, and east components. 

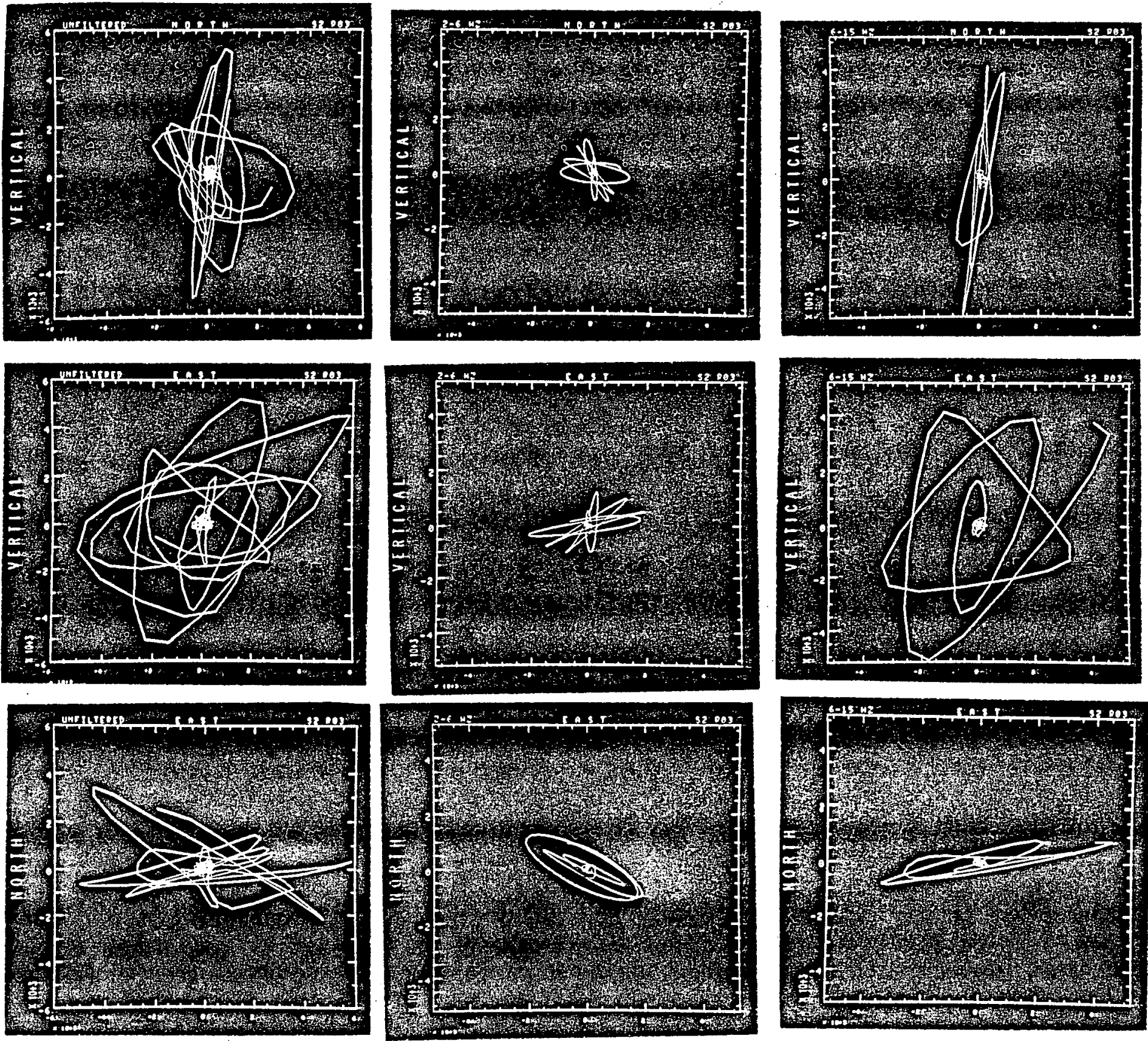

Figure 3. Typical particle motion plots. (a) unfiltered data, (b) bandpass filtered $2-6 \mathbf{H z}$, (c) bandpass filtered 6-15 Hz. From top to bottom, the projections are vertical-north, vertical-east, and northeast planes. 


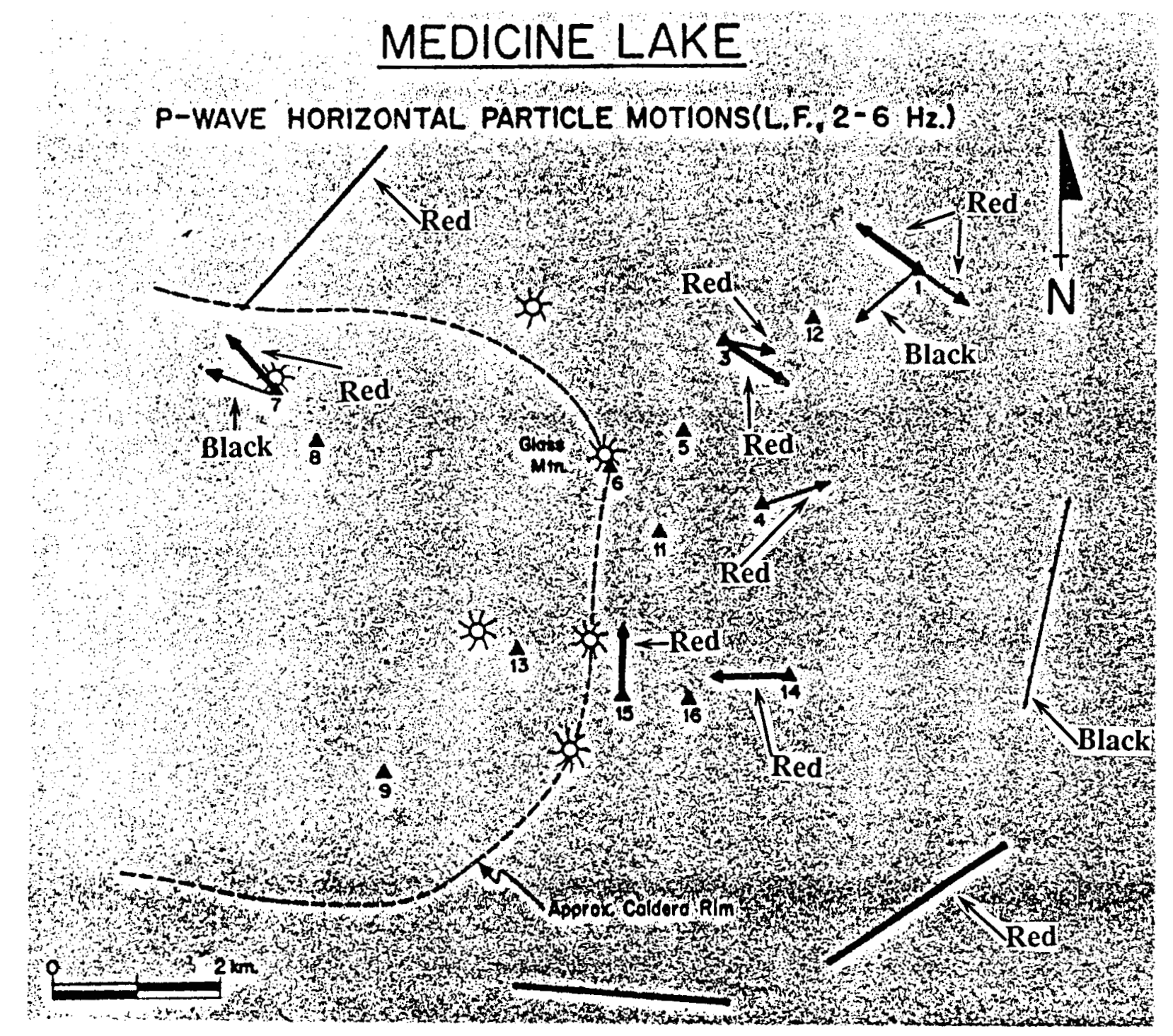

Figure 4. Directions of first particle motions for data bandpass filtered $2-6 \mathrm{~Hz}$. Arrows indicating direction are drawn in the same color as the theoretical wavefronts from the source, which are indicated by colored lines near the border of the figure.

ized at each station, so the maximum magnitudes at all stations are the same and differences in magnitude between stations are meaningless.

To examine the directions of polarization of the first few P-wave cycles, stereographic projections of the particle motion in the hemispheres above and below the horizontal plane were plotted. The stereographic projections showed all sampled points of the particle motion during approximately a second of data starting at the first P-arrival. Those points closest to the maximum displacement of the particle trajectory from rest were marked. Since only P-waves were present, the maximum displacement points gave the direction of arrival of the particular phase. The original particle position (position of the particle at rest) and the maximum displacements of the first three or four cycles tended to be coplanar, but no conclusions were drawn from this.

\section{Results of Modeling}

It is not possible to invert the data in this study because the small number of available 


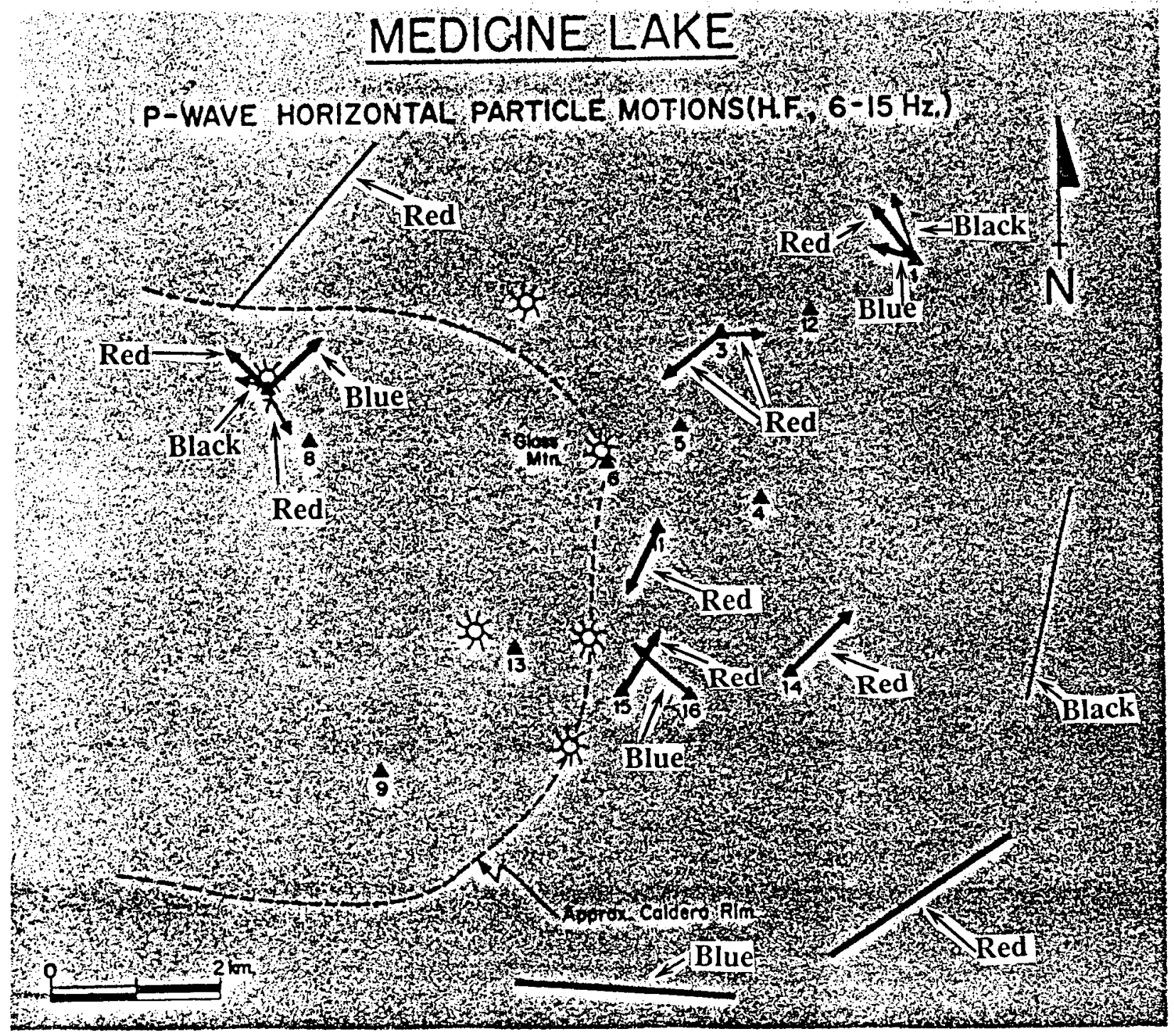

Figure 5. Same as Fig. 4 but for data bandpass filtered 6-15 Hz.

records and lack of resolution of available models makes the problem highly non-unique. However, we can find plausible geologic models that are consistent with, and therefore could explain, the data. This is an important point which indicates that further work on this topic using more extensive data sets is warranted.

A three-dimensional ray-tracing program that includes computation of $\mathrm{P}$-wave polarities was used to attempt to model the data. The program computes the wavefield at the surface which results from energy passing through a multiple-parameter curved interface that separates material of different wave velocities. Later arrivals due to reflections with the interface and the free surface can also be computed. Zucca [personal communication] found evidence of a low-velocity feature in the vicinity of the receivers, and this may be responsible for particle motions at the receivers.

A plausible model that explains the direct arrivals is a sausage-like low-velocity zone situated with its major axis trending northsouth. Its center is located approximately midway between stations 11,15 , and 16 . The low-velocity zone is about $5-\mathrm{km}$ deep, $9-\mathrm{km}$ 
wide, 16- $\mathrm{km}$ long, and has a refractive index of 0.4. In a qualitative sense, this model accounted well for about $75 \%$ of the data, and fit the high-frequency filtered data better than the low-frequency filtered data. The computed wavefields for the shot points considered are shown in Fig. 6. The arrows in the computer simulations are projections on the horizontal plane of the computed first Pwave motion directions. No amplitude effects were considered, so very short arrows indicate largely vertical motion. The later arrivals in the P-wave train were not explained by the computed theoretical later arrivals. This is probably due to the simplicity of the model.

Some of the anomalous data in Figs. 3 and 4 could be explained well by the lowvelocity model, but some could not. In the low-frequency $(2-6 \mathrm{~Hz})$ data, the shot 2 particle motions at receivers 14 and 15 are anomalously focused towards the center of the hypothetical low-velocity zone, while those at receivers 1 and 7 are undisturbed. Both of these effects appear in the computer simulations. Data from shots 3 and 4, with one exception, are less distributed than in the computer simulations. This is perhaps a result of these low frequencies being less susceptible to the influences of small-scale structure. The exception is shot 4 at receiver 1, which shows focusing towards the center of the hypothetical low-velocity zone, but in the computer simulations it is too far from this zone to feel its effects.

In the high-frequency $(6-15 \mathrm{~Hz})$ data, shots 2 and 6 show best the focusing that could be caused by a low-velocity structure like the one simulated. For shot 2, data at receivers 3,11 , and 15 are strongly focused towards the center of the hypothetical lowvelocity zone, data at receiver 1 is slightly affected, and data at receiver 7 is unaffected. These effects are all shown in the computer simulation. Data at receiver 14 , however, are not explained. For shot 6 , the focusing of data at receivers 1,7 , and 16 towards the hypothetical low-velocity zone center all correspondence well to the computer simulations. The data from shots 3 and 4 do not correspond quite as well to the computer simulations.

\section{Discussion}

The results seem to suggest that the dominant effect on the particle motions at the stations studied could be low-velocity volume under the stations trending north-south and extending beyond the southern range of the stations. The characteristics of the particle motions that lead to this conclusion are not observable with vertical-only instruments. Unfortunately, this study is limited by the paucity of good data, but this defect is well suited to the simplicity of the available simulation models. However, the success of this investigation in finding a geologically reasonable model that is consistent with the observed data, and not resolvable from vertical-only data, indicates that further work using threedimensional data could yield valuable results. It is reasonable to expect that in an area with an appropriately dense array of vertical instruments, the incorporation of three-component instruments throughout the array may substantially decrease the non-uniqueness of the inverse problem. The number of threecomponent sensors that best complements a vertical-only array should be between $10 \%$ and $20 \%$ of the total (see Sorauf and Rial, 1988).

\section{References}

Sorauf, C., and J. A. Rial, "A Numerical Study of Caustics and Polarizations of Seismic Waves Interacting with Three-Dimensional Geologic Structures," Applied Num. Math. 4, 71-81, 1988.

\footnotetext{
Zucca, J. J., G. S. Fruis, B. Milkereit, W. D. Mooney, and R. D. Catchings, "Crustal Structure of Northeastern California," $J$. Geophys. Res. 91, 7359-7382, 1986.
} 

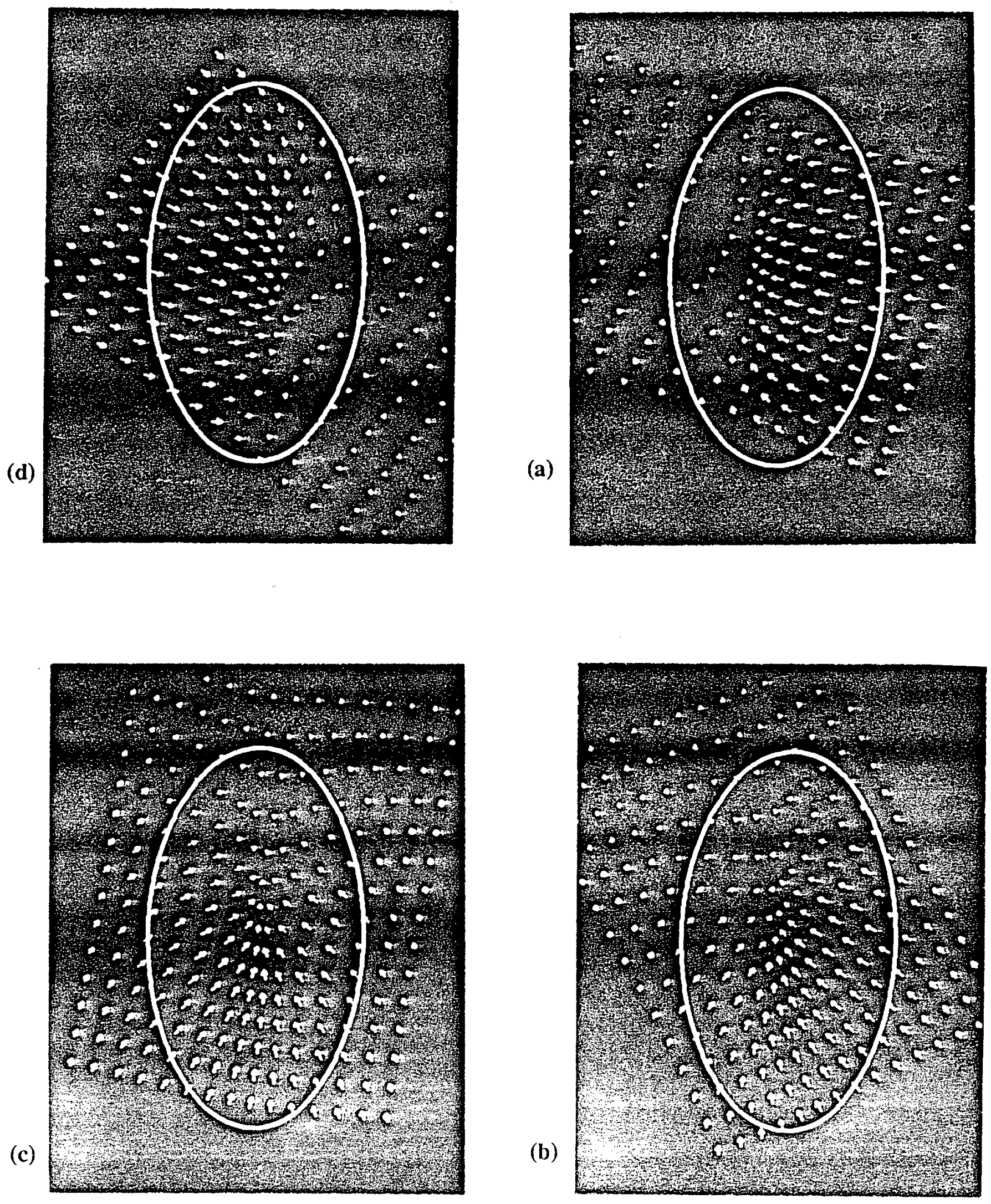

Figure 6. Simulated particle motions. The white ellipse is the outline of the Gaussian interface at depth 1/e times the maximum interface depth. Shots are at (a) shot point 4, (b) shot point 2, (c) shot point 6 , and (d) shot point 3 . 
